\title{
Medicine as a profession: times of change
}

\author{
David Armstrong
}

Department of Public Health Medicine, United Medical and Dental Schools of Guy's Campus and St Thomas's Hospitals, London SE1 9RT

David Armstrong, FFPHM, reader in sociology as applied

BrMed f 1990;301:691-3

"Doctors Prefer Shell" by Graham Sutherland (1934). This was one of a series of Shell posters aimed at professional groups to medicine

Work and the organisation of work is an important facet of social life. On the one hand the increasing division of labour after the Industrial Revolution destroyed the sense of community that came from shared work; on the other hand occupations and occupational groups have seemed to be one of the few areas in which a new sense of personal and group identity might emerge in modern society. This potential seems to have been most successfully realised in a special sort of occupational group known as a profession.

The wider social importance of the professions as bodies that mediated between the individual and the state was first pointed out by the French sociologist Emile Durkheim,' but it was Carr-Saunders's and Wilson's The Professions of 1933 that first gave full recognition to their central role in modern society ${ }^{2}$; they argued that professional associations were stabilising elements in society, engendering "modes of life, habits of thought, and standards of judgment which render them centres of resistance to crude forces which threaten steady and peaceful evolution." Professions as essentially altruistic self governing communities were the ideological bulwark of liberal democracy.

\section{The professionalisation of everyone}

In the years after the second world war social analysts turned increasingly to echo the view of CarrSaunders and Wilson of the professions as important elements in social activity. Whereas so much of social life was regulated directly by the state or indirectly by the vicissitudes of the market place the professions represented occupational groups, organised like mediaeval guilds, which successfully managed to police themselves for the apparent greater good of all. ${ }^{3}$ The history and nature of professions, in particular that of medicine, thus became the object of intensive study and debate.

The attributes of the medical profession were explored in great detail to establish the particular characteristics that were necessary to transform an ordinary occupation into a powerful profession. ${ }^{4}$ Long lists of traits were produced, many of them documenting a sort of natural history of "professionalisation"

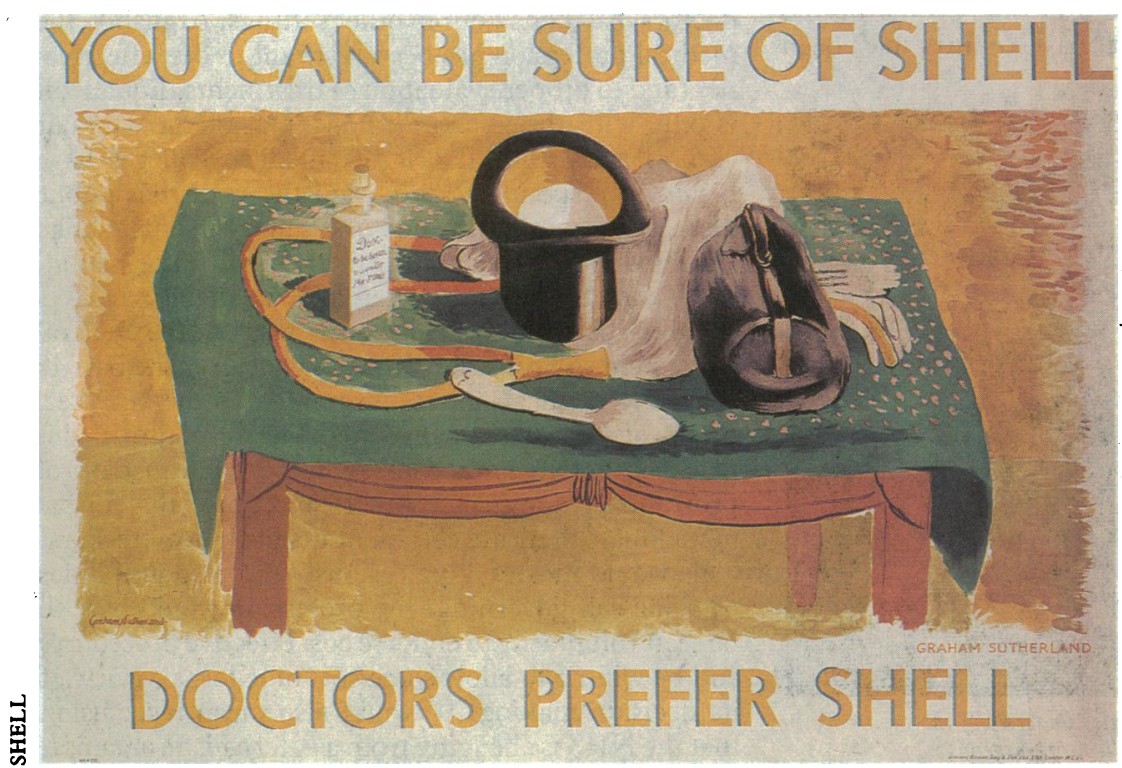

through which aspirant occupations could achieve similar high status and respect. ${ }^{5}$ Yet there were two core characteristics to be found in all these "essential" professional attributes: esoteric knowledge-which meant that professionals were clearly experts in relation to their client-and a service ideal in which altruistic motives eclipsed simple greed and the threat of exploiting a monopoly of specialist knowledge.

This fascination with professions and professionalisation led to the thesis that all occupations in modern society were busy professionalising and all could be ranked on a continuum from mundane, market driven occupations through to the medical profession itself. ${ }^{5}$ Thus occupations in the wider health division of labour-nursing, physiotherapy, radiography, etccould be seen to be transforming themselves into professions by strategies such as increased education, proper registration and licensing, the exclusion of "dirty work," and adherence to explicit ethical codes. ${ }^{6}$

As for the medical profession, its apparent expertise and self disinterest ensured that it was given major responsibility for health service resources as an expanded welfare state increased the monies pouring into health care. It meant that the medical profession could be given the task of organising the health division of labour so that "professions supplementary to medicine" could be properly developed under medical supervision. But, despite these obvious successes, perhaps the greatest achievement of the medical profession in the two immediate postwar decades was to win general acceptance for its self professed altruism and expertise which, coincidentally, brought it new found wealth, status, and influence.

\section{The importance of clinical autonomy}

Sociologists usually point to Freidson's Profession of Medicine: a Study of the Sociology of Applied Knowledge of 1970 to mark the point when the image of the medical profession began to tarnish. ' In essence, Freidson suggested that a little more self interest in the recent history of the medical profession might be disclosed on closer examination than the profession itself was willing to acknowledge. In this new analysis the success of a profession was not due to possessing the requisite "core traits" such as esoteric knowledge, a service ideal, and so on, but depended entirely on the degree of control the profession had managed to establish over the conduct of its own work. Medical power, therefore, rested on a high degree of autonomy in clinical work, which medicine had successfully claimed as its natural right. In this light the power and status of medicine could simply be interpreted as the result of skilfully exploiting a marketing opportunity in health care $^{89}$ : Shaw's description of professions as being conspiracies against the laity now seemed remarkably prescient. ${ }^{10}$

At the same time as this major revision to the sociological analysis of professions, others began to remove their rose tinted spectacles. In maintaining control over clinical work the medical profession established jurisdiction over the distribution of health care resources. But successive governments that provided these resources became increasingly frustrated that their priorities, such as the care of the chronically ill, were frequently ignored by the medical profession. Thus from the mid-1960s the government began the first of a series of bids to reform the NHS, which in retrospect can all be seen as attempts to curtail the 
control that the medical profession exerts over health. resource allocation. Gradually under this pressure the image of the medical profession was transformed from a bastion of altruism to simply another, if uncommonly powerful, vested interest.

\section{The threat of deprofessionalisation}

Despite the American Medical Association's emotive rejection of socialised medicine because of its supposed threat to medical autonomy the British doctor by and large maintains more freedom of action than his or her American counterpart. In effect the same process that now threatens the medical profession in Britain has already had considerable influence on health care provision in the United States, and clinical autonomy has suffered a commensurate decline over the past two decades. Again, it has been the funding bodieswhether government, insurance companies, or employers - who have attempted to contain runaway costs by placing successively more severe restrictions on clinical freedom. Thus American doctors increasingly find themselves working to clinical guidelines as laid down by corporate and government sponsors. For example, many insurance groups now use a diagnosis related group system (which limits the costs of treatment to the nature of the patient's diagnosis) to effect payment to hospitals, who in their turn reimburse doctors. Indeed, in some parts of the American health care system doctors are finding that their attempts to admit patients to hospital are failing because the clinical picture does not match the agreed admission protocol. As if to rub salt into the wound these protocols and the decisions that flow from them are often administered by nurses.

Thus it has been argued that the medical profession in the United States is being "deprofessionalised" as doctors lose clinical autonomy and simply become agents or employees of corporate providers of health care. " In part, doctors in the United States have accepted these constraints because they have usually had little choice, but their resistance has been muted in so far as these constraints have not, at least so far, threatened their incomes.

Similar forces seem to be at work within the British National Health Service. Indeed the most recent government proposals for reforming the health service offer the severest challenge so far to clinical autonomy in that it is proposed to remove many medical decisions from doctors and give them to managers who will act according to market forces. ${ }^{12}$ Doctors will thus find their clinical autonomy threatened and power devolved to local managers and consumers.

Johnson has pointed out that the power of the medical profession over the past century has been

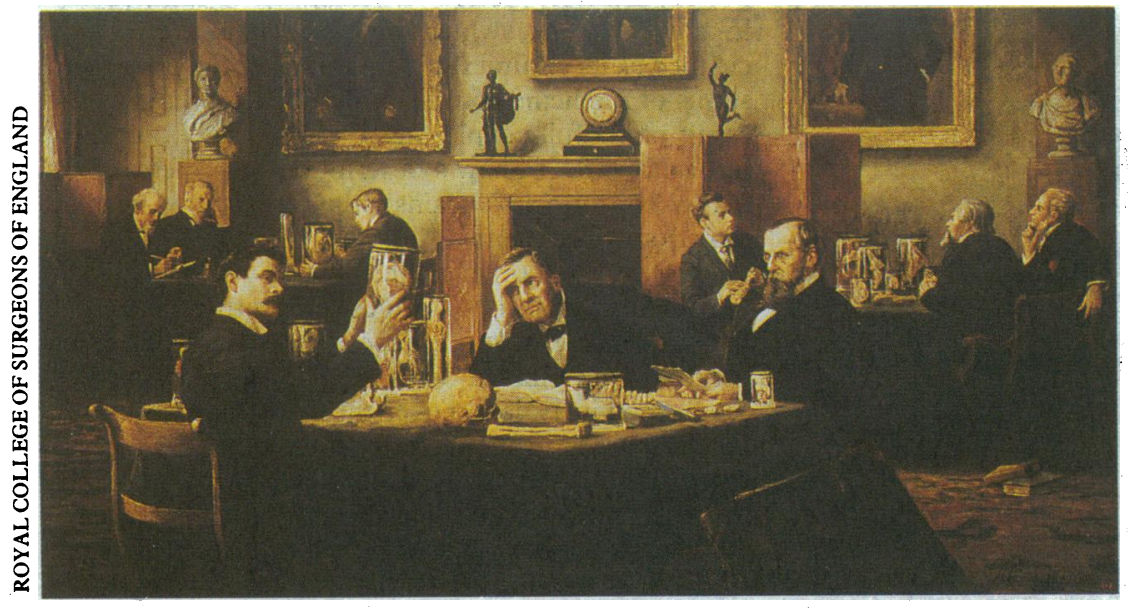

"Court of Examiners" by Henry famyn Brooks (1894). Three candidates undergoing the viva voce in surgical pathology in the final examination for fellowship of the Royal College of Surgeons based on doctors organising themselves into a system of collegiate con̆trol and then applying pressures to gain considerable freedom over the content of their work. ${ }^{13}$ Before this model of professional accountability, when patient patronage was the norm, the medical profession was much less powerful or unified.

Will increasing government intervention into the way that health care is provided mean a return to a sort of government or corporate patronage in which medical power is reduced or destroyed? On the one hand the intrusion of non-clinical managers threatens the profession's control over its work, and on other hand the introduction of more market forces into the provision of health care may challenge the unity of the profession.

Yet while medicine has to fight to maintain the gains of professional status it must also contend with those other groups that, in emulating medicine, have pursued professionalising strategies of their own. The attempt by the medical profession to supervise the wider health division of labour has failed as these aspirant groups have pursued their own professionalising strategieswhich meant, for a start, breaking free from medical tutelage. ${ }^{14}$ Paramedical groups have now become increasingly vocal in their demands for autonomy in their work, and these claims often cross the boundary into traditional medical tasks. Outside the NHS there is an increasing number of alternative practitioners who, with their increasing public acceptance, are in a position to challenge the supposed uniqueness of medicine's specialist healing knowledge. And finally, the professionalising process has continued within medicine itself as new specialties claim jurisdiction over certain parts of medical work while seeking the trappings of professional status, such as examinations, colleges, journals, meetings, etc. The old style general physician or general surgeon is becoming an endangered species. But perhaps the major internal threat is that provided by the increasing polarisation of the medical profession between hospital and primary care physicians: from being the second class citizens of medicine primary care doctors have rapidly improved their position and may further their control over the hospital sector with the proposed NHS reforms.

\section{Failure of policy}

In retrospect it might be claimed that it was the medical profession's failure to police itself adequately that has led to these difficulties. Of course the profession has traditionally monitored its members' conduct through the General Medical Council, but until very recently the council has deliberately shied away from issues of clinical competence and concentrated on doctors' bad behaviour in other settings. Arguably, the medical profession has been resistant to cost effectiveness and to proper evaluation of treatments. Equally, it is only with the government's threat of carrying out clinical audit that at last the medical colleges have begun to respond in kind. And the recurrent public disenchantment with doctors' interpersonal skills, particularly in giving information and explanation, has fuelled the switch to alternative medicine.

From being the clear beneficiary of the general movement to professionalise everyone over the past 40 years the medical profession now faces the very real threat of deprofessionalisation. The response to this threat is not to hark back to some halcyon days of professional dominance but to recognise that in the new climate there are certain limits to clinical freedom. This would mean taking seriously the responsibilities of being self governing: the profession would have to be seen voluntarily to endorse cost effective procedures and be willing to allow some sort of external review of its decision making. It would also mean recognising that the NHS is changing from a paternalistic organisa- 
tion in which professional and administrative interests decide what the consumer needs to a service that is more responsive to the higher expectations and wishes of the patients. Doctors will have to learn that a satisfied patient is as important as a medically improved one. The implications of these changes for traditional medical education and practice, which have always implicitly emphasised the importance of professional dominance, are considerable but reflect a historical transformation to the environment in which professions now operate.

1 Durkheim E. The division of labour in society. New York: Macmillan, 1933 2 Carr-Saunders AM, Wilson PA. The professions. Oxford: Oxford University Press, 1933. (Reprinted by Frank Cass, London, 1964.)
3 Goode WJ. Community within a community, the professions. American Sociological Review 1957;22:194-200.

4 Millerson G. The qualifying associations: a study in professionalisation. London: Routledge and Kegan Paul, 1964.

5 Wilensky HL. The professionalisation of everyone? American fournal of Sociology 1964;70:137-58.

6 Etzione A. The semi-professions and their organisation. New York: Free Press, 1969.

7 Freidson E. Profession of medicine: a study of the sociology of applied knowledge. New York: Dodd Mead, 1970.

8 Berlant JL. Professions and monopoly: a study of medicine in the United States and Great Britain. Berkeley: University of California Press, 1975.

9 Larson MS. The rise of professionalism. Berkelev: University of California Press, 1977.

10 Shaw GB. The doctor's dilemma. London: Constable, 1926.

11 Starr P. The social transformation of American medicine. New York: Basic Books, 1982.

12 Department of Health and Social Security. Promoting better health. London: HMSO, 1987.

13 Johnson T. Professions and power. London: Macmillan, 1972.

14 Larkin G. Occupational monopoly and modern medicine. London: Tavistock, 1983.

\section{Fading Away (1858)}

Photograph by Henry Peach Robinson (18301901; British)

Although the invention of photography in the mid-nineteenth century had a profound influence on painting, many photographers achieved their effects through painterly means. Henry Peach Robinson was one of them. A talented draughtsman, he sketched his subjects before photographing them and then divided his completed compositions into sections, which he then photographed separately. Finally, he pasted each cut out section on to a ready prepared background. "Fading Away" is a combination print made from five negatives. At first it looks like a monochrome reproduction of a

painting, and that surely is its strength. The scudding clouds seen through the window prevent the photograph from being static and at the same time add to the gloom of the atmosphere.

\section{CLASSIC OF THE DECADE}

1858: Rudolf Virchow's Die Cellularpathologie in Ihrer Begründung auf Physiologische und Pathologische Gewebelehre. Berlin: A Hirschwald.

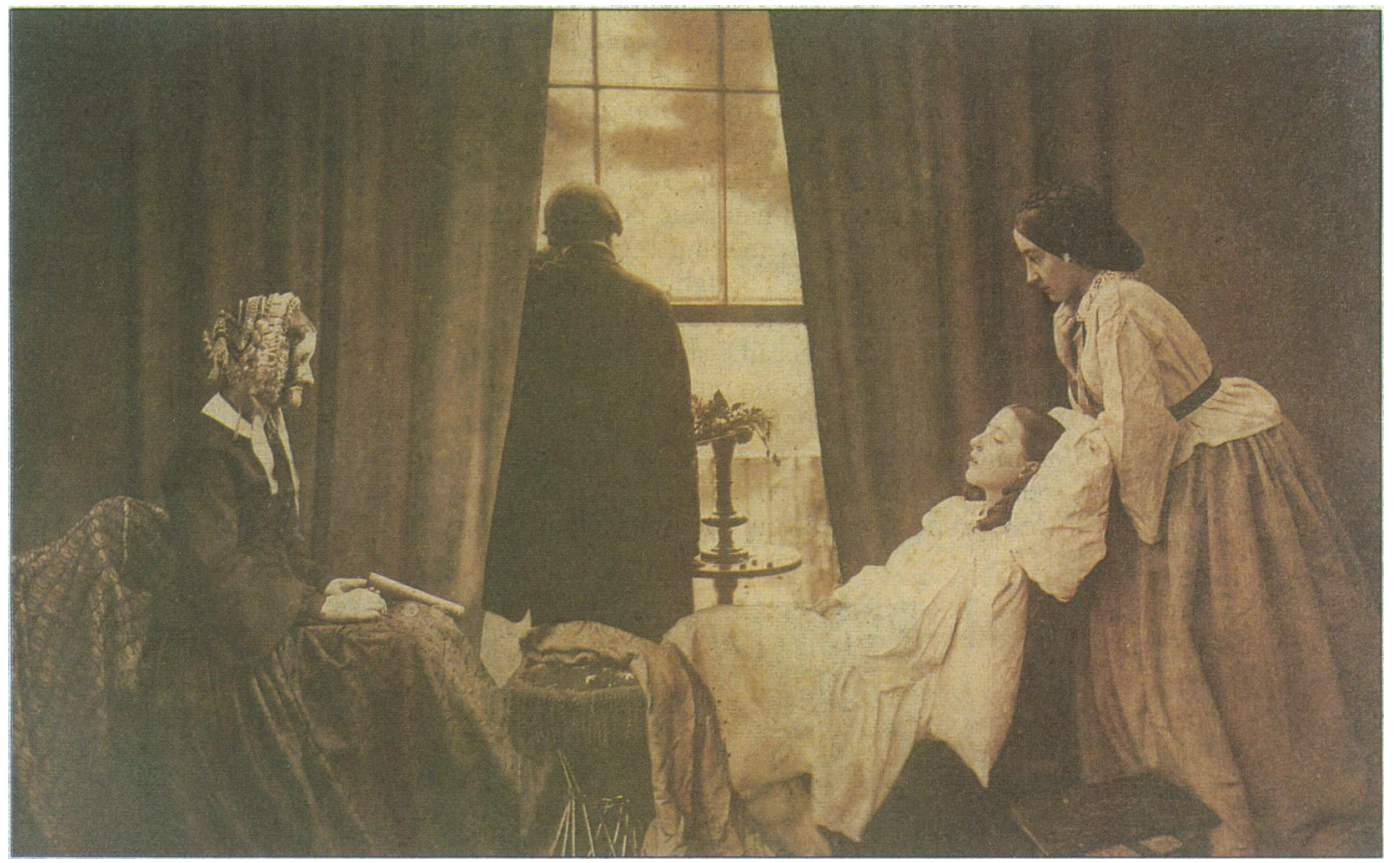

